\title{
Human responses to various conditions of water temperature'
}

\author{
PAUL J. WOODS, BEVERLY A. GRIFFITH AND RUTH P. PAGE, HOLLINS COLLEGE \\ PATRICIA M. RODIER, UNIVERSITY OF VIRGINIA
}

Skin-surface temperatures on the human hand were obtained immediately following six exposure times ranging from 5 to $60 \mathrm{sec}$. for water temperatures varying in $5^{\circ}$ increments from $10^{\circ}$ to $40^{\circ} \mathrm{C}$. The surface of the skin was found to respond rapidly and regularly to both the temperature and time of exposure. In a second study $30 \mathrm{~S}$ s exposed a hand for 5 or $30 \mathrm{sec}$. to water temperatures ranging from $10^{\circ}$ to $45^{\circ} \mathrm{C}$. and made ratings on scales of pain and comfort as well as attaching a verbal lajel (cold, cool, tepid, etc.) to each experience. The experience of cold became more intense over these time intervals while the experience of warmth became less, and with the threshold constant taken into account the sensations of pain and discomfort were found to follow a psychophysical power law. The usefulness of these sorts of data for interpreting the effects of noxious stimuli in basic learning studies is discussed.

Variations in water temperature have been demonstrated to be an effective means for manipulating drive stimulus intensity and reinforcement magnitude in escape conditioning (Woods, Davidson, \& Peters, 1964; Woods \& Schutz, 1965; Woods \& Feldman, 1966; Woods \& Holland, 1966). As an adjunct to this research with animals, it would be useful to have this noxious stimulus dimension scaled in various ways by human Ss. But first, at an even more basic level, the actual skin-surface temperature which leads to the psychological sensations should be studied. Therefore, Experiment I deals with the determination of skin-surface temperature immediately following various exposure temperatures and times. Then, in ExperimentII, human Ss attached verbal labels to various temperatures following two exposure times and also rated their sensations on scales of pain and comfort.

\section{Subjects}

\section{EXPERIMENT I}

All measurements were taken from the hand of one human female (P. M. R.).

\section{Apparatus}

An electronic thermometer (YSI Model 46TUC) equipped with a banjo thermistor probe was used to take the readings and the output was run into a Beckman potentiometric recorder so that a continuous record of temperature change over time was obtained. The calibration of the electronic thermometer was checked against a standardized thermometer from the National Bureau of Standards.
Two water baths were prepared, one at $32^{\circ} \mathrm{C}$ and the other at the exposure temperature to be studied. The water temperature in each bath was controlled automatically by a constant temperature circulator which maintained the temperature within $\pm 0.1^{\circ} \mathrm{C}$ of any desired level.

\section{Procedure}

All measurements were taken from the palmar surface of the hand in the region of Palmaris brevis muscle. Prior to exposure the hand was immersed in the $32^{\circ} \mathrm{C}$ bath until its temperature stabilized at this level. The hand was then dried and immersed to the wrist in the exposure tank and moved back and forth to prevent a local warming of the bath. The exposure time was measured by a stopwatch, and following the given exposure time the hand was removed, quickly dried at the site to be measured to avoid having the data influenced by evaporation, and the probe was maintained in contact with the site until the temperature had returned to normal. The ambient air temperature in the laboratory averaged $23.7^{\circ} \mathrm{C}$ with a standard deviation of $1.06^{\circ} \mathrm{C}$ over all sessions. Three separate measurements were obtained in each of six different exposure times ranging from 5 to 60 sec. at temperature conditions ranging from $10^{\circ}$ to $40^{\circ} \mathrm{C}$.



Fig. 1. Skin-surface temperature on the human hand as a function of exposure time and water-bath temperature. 




Fig. 2. Temperature sensations following 5-sec. water-bath exposures of the human hand.

\section{Results}

The average skin surface temperature immediately following immersion is plotted in Fig. $1 .{ }^{2}$ As can be seen, these data are quite uniform. They are also highly reliable with only slight variations among the three repeated measures taken for each of the conditions. Clearly, the temperature of the surface of the skin responds rapidly to the temperature of the water in which it is immersed and this response is directly related to both the time of exposure and the temperature. ${ }^{3}$

As would be expected, the time for the skin to return to normal is also a direct function of the time and temperature of exposure. With the lower temperatures and longer exposure times skin-surface temperature during the recovery period would "overshoot" the normal level as much as several degrees and take quite some time before returning to a stable $32^{\circ} \mathrm{C}$. This result is undoubtedly due to the coldinduced vasodilation known as the Lewis phenomenon.

\section{EXPERIMENT ॥}

\section{Subjects}

Thirty young-adult volunteers (10 males and 20 females) were used.

\section{Apparatus}

A large tank whose temperature was automatically controlled within $\pm 0.1^{\circ} \mathrm{C}$ by a constant temperature circulator was used for returning all subjects' hands to $32^{\circ} \mathrm{C}$ prior to each exposure. A series of plastic buckets was used to contain the comparison temperatures, and these were adjusted prior to each judgment to within less than $\pm 0.1^{\circ} \mathrm{C}$ of the desired level.

\section{Procedure}

The subjects were run individually by two experimenters. They were given the following scales to use. First, a verbal label of biting or painfully cold, cold, cool, tepid, warm, hot, and burning hot. Second, a 5 point pain scale ranging from none to excruciating and a 5 point comfort scale ranging from very uncomfortable to very comfortable. They were instructed not to make their ratings until the end of the exposure time. There were two exposure times of 5 and 30 sec. at each of eight temperature conditions ranging in $5^{\circ}$ increments from $10^{\circ}$ to $45^{\circ} \mathrm{C}$. Prior to each exposure condition, $\mathrm{S}^{\prime} \mathrm{s}$ hand was stabilized at $32^{\circ} \mathrm{C}$ by placing it in the adaptation tank for 30 to $60 \mathrm{sec}$. The hand was then thoroughly dried and at a ready signal was immersed for the given exposure time. One experimenter then called for the judgment when the exposure time had elapsed, and the $\mathbf{S}$ removed his hand and made his ratings.

\section{Resulis}

The percentage of subjects using the various verbal labels for each condition are shown in Figs. 2 and 3 for the two exposure times. Our procedure, with massive stimulation of the entire surface of the hand by water, yields important differences from the classic results of von Frey reproduced by Boring (1942, p. 505). Our data indicate that for a group of Ss the thermal sensations clearly overlap to a considerable extent, and, furthermore, show definite changes as a function of time of exposure. The experience at the cold end becomes more intense with time while the experience at the warm end becomes somewhat less intense. This finding is also supported by the results from the pain and comfort scales. Figures 4 and 5 show the percentage of Ss responding with the various points on the pain scale. (The three higher points have all been grouped together and are plotted as "painful.") If we define a pain threshold as the point where $50 \%$ of the Ss report their experience as at least "clearly painful," then the pain threshold at the cold end for a 5-sec. exposure is $11.5^{\circ} \mathrm{C}$; after 30 sec. the threshold has moved $4^{\circ} \mathrm{C}$ closer to physiological zero. Whereas at the warm end of the scale the threshold was $44^{\circ} \mathrm{C}$ after $5 \mathrm{sec}$., and it moved $1.5^{\circ} \mathrm{C}$ further away from physiological zero after



Fig. 3. Temperature sensations following 30-sec. water-bath exposures of the human hand. 


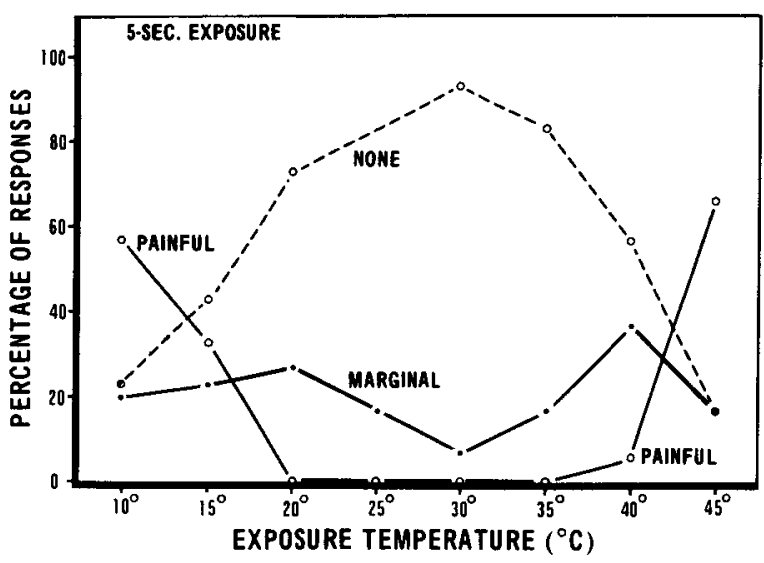

Fig. 4. Ratings on a pain scale following 5-sec. water-bath exposures of the human hand.

30 sec. 4 The von Frey diagram shows the initiation of pain below $15^{\circ} \mathrm{C}$ and above $50^{\circ} \mathrm{C}$. In marked contrast to these results, fully $60 \%$ of our Ss report clear pain with a $30-$ sec. exposure to $15^{\circ} \mathrm{C}$ and $67 \%$ report clear pain after $5 \mathrm{sec}$. at $45^{\circ} \mathrm{C}$.

The differential changes with time at the two ends of the scale are also reflected in the comfort ratings shown in Figs. 6 and 7. The cold end of the scale becomes more uncomfortable with increased exposure while the warm end of the scale becomes less uncomfortable. Also note that with increased exposure to the cold end of the scale, it is generally the neutral sensations which change to uncomfortable ones.

Recently Gagge and Stevens (1966) have reported work investigating whether thermal discomfort obeys a refined version of the psychophysical power law which takes into account the value of the stimulus at absolute threshold. A threshold constant (physiological zero) is needed with thermal continua because its value constitutes a sizeable portion of the permissible range of thermal stimulation. With a very sophisticated and elaborate procedure involving wholebody exposure to variations in air temperature they did, indeed, find that discomfort obeyed the same



Fig. 6. Ratings on a comfort scale following 5-sec. water-bath exposures of the human hand.

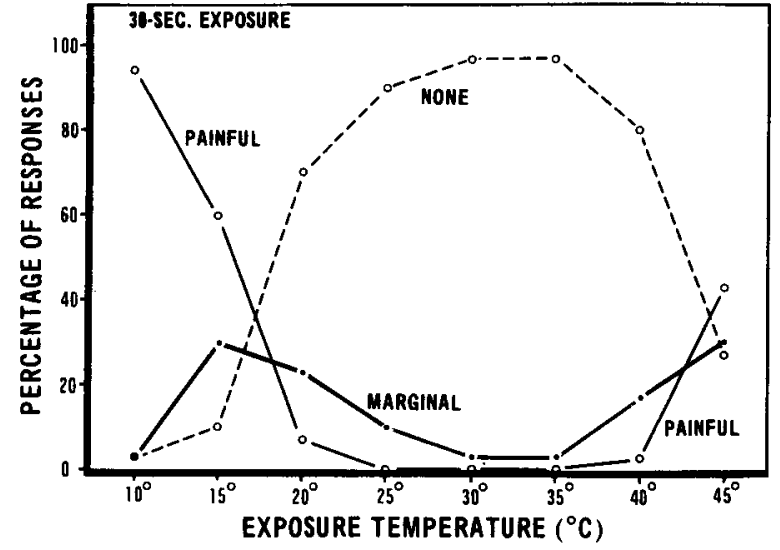

Fig. 5. Ratings on a pain scale following 30-sec. water-bath exposures of the human hand.

psychophysical power law that describes sensation on many other continua. They report different slopes for warm and cold discomfort with a faster rate of increasing discomfort on the cold side of the stimulus scale.

There aren't sufficient data points in our results to ascertain whether there are differential slopes for cold and warm discomfort with hand exposure to water temperature, but we can ascertain, at least on a preliminary basis, whether the revised psychophysical power law seems to apply here as well.

Following the procedure of Gagge and Stevens (1966) we have calculated the geometric means of the $30-\mathrm{sec}$. exposure discomfort ratings and plotted them against the difference of the exposure temperature from physiological zero (taken as $31^{\circ} \mathrm{C}$ ) on log scales. These results are shown in Fig. 8 with the two warm and three cold discomfort points indicated. The straight-line fit to these data points clearly indicates a power function.

The data obtained with the pain ratings following a 30-sec. exposure were treated in the same fashion. The results shown in Fig. 9 again clearly indicate a power function.

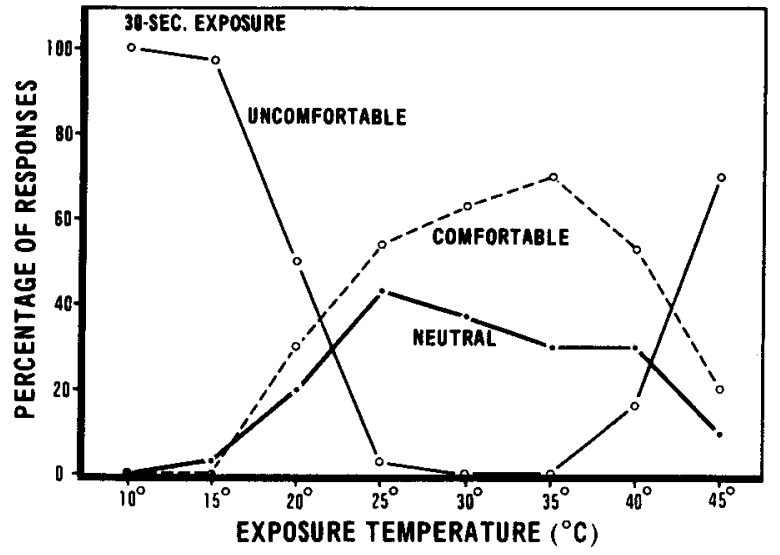

Fig. 7. Ratings on a comfort scale following 30-sec. water-bath exposures of the human hand. 


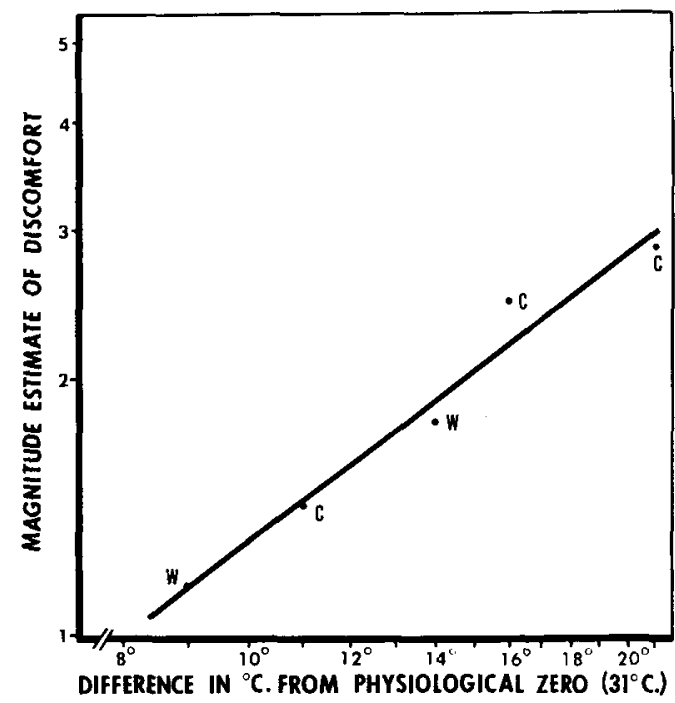

Fig. 8. Magnitude estimates of discomfort following 30-sec. water-bath exposures of the human hand. Warm (W) and cold (C) points are indicated.

\section{DISCUSSION}

While the various findings reported in this paper are related to work on thermal sensations, the experimental context in which they were developed is quite different. The intent of these studies was to aid in the understanding and interpretation of results where water temperature has been used as an effective means of motivating and reinforcing animals in an instrumental escape conditioning paradigm. Exposure to water actually presents difficulties for the study of the intensity of warmth and cold per se (Stevens \& Stevens, 1960), and far more sophisticated procedures have been developed for the study of thermal sensitivity per se (Kenshalo, Nafe, \& Dawson, 1960). The data from the present studies, on the other hand, may actually be more relevant to the gross bodily stimulation which is entailed in the escape conditioning situation. And since it is conceivable to obtain similar human responses on other noxious stimulus dimensions, we can expect to couple these comparisons along with work dealing with inter-dimensional scaling (Campbell \& Bloom, 1965; Woods, 1965) to gain a better understanding of the effects of manipulating noxious stimulus dimensions in basic learning research.

\section{References}

Boring, E. G. Sensation and perception in the history of experimental psychology. New York: Appleton-Century, 1942.

Campbell, B. A., \& Bloom, J. M. Relative aversiveness of noise and shock. J. comp. physiol. Psychol, 1965, 60, 440-442.

Gagge, A. P., \& Stevens, J. C. Thermal sensitivity and comfort. Paper read at An International Symposium on the Skin Senses, Tallahassee, Florida, March, 1966.

Hardy, J. D., Goodell, H., \& Wollf, H. G. The influence of skin temperature upon the pain threshold as evoked by thermal radiation. Science, $1951,114,149-150$.

Kenshalo, D. R., Nafe, J. P., \& Dawson, W. W. A new method for the investigation of thermal sensitivity. J. Psychol., 1960,49, 29-41.

Stevens, J. C., \& Stevens, S. S. Warmth and cold: dynamics of

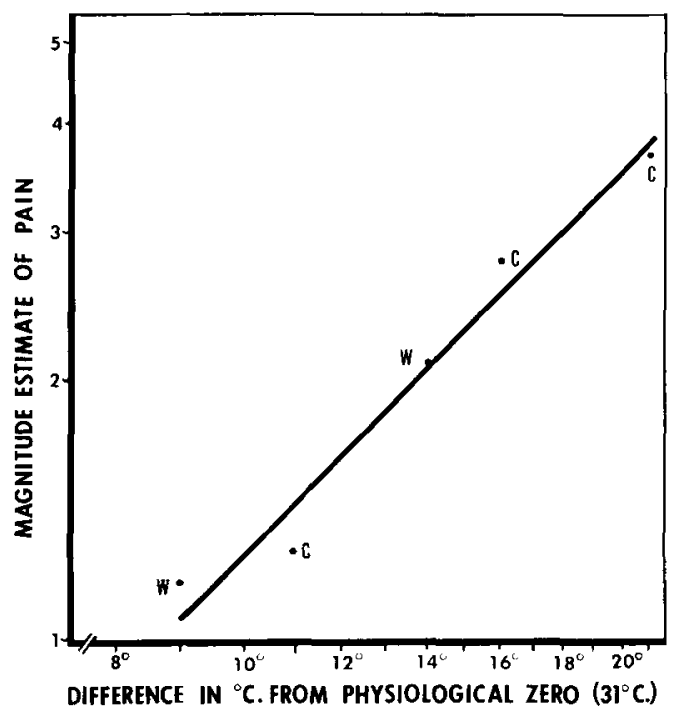

Fig. 9. Magnitude estimates of pain following $30-\mathrm{sec}$. water-bath exposures of the human hand. Warm $(W)$ and cold $(C)$ points are indicated.

sensory intensity. $J$. exp. Psychol., 1960, 60, 183-192.

Woods, P. J. The scaling of aversive stimuli. Paper read at Psychonomic Society Meeting, Chicago, October, 1965.

Woods, P. J., Davidson, E. H., \& Peters, R. J., Jr. Instrumental escape conditioning in a water tank: effects of variations in drive stimulus intensity and reinforcement magnitude. $J$. comp. physiol. Psychol., 1964, 57, 466-470.

Woods, P. J., \& Feldman, G. B. The combination of magnitude and delay of reinforcement in instrumental escape conditioning. $J$. comp. physiol. Psychol., 1966, 62, 149-151.

Woods, P. J., \& Holland, C. H. Instrumental escape conditioning in a water tank: effects of constant reinforcement at different points on the continuum of drive stimulus intensity. $J$. comp. physiol. Psychol., 1966, 62, 403-408.

Woods, P. J., \& Schutz, L. J. Performance in instrumental escape conditioning following a shift in drive stimulus intensity. Proc. 73rd Ann. Conv. Amer. Psychol. Assoc., 1965, 23 24.

\section{Notes}

1. This work was supported in part by Public Health Service Research Grant M-02883 from the National Institute of Mental Health, and in part by a Science Education Grant from the National Science Foundation.

2. The skin surface temperature, of course, had already begun to recover to normal by the time we were able to take the measurements. The temperature of the outer surface during exposure is probably very close to the temperature of the surrounding bath. 3. We attempted to obtain similar data from shaved portions of a rat's hip and stomach. These data were comparable to those shown in Fig. 1 in that the skin surface temperature responded rapidly and varied directly as a function of both time and exposure temperature. There was, however, much greater variability in these data which was produced in part by the struggling of $S$ even under highly restrained conditions. The struggling, of course, would influence the body temperature and thereby interfere with precise measurements of changes in skin surface temperature. The idea of using an anesthetized animal was discarded because anesthesia lowers body temperature.

4. These results are very similar to the pain threshold for thermal radiation of $44.9^{\circ} \mathrm{C}$. reported by Hardy et al (1951). Their tesults indicated that this temperature must be reached by the surface of the skin for pain to be perceived regardless of the initial temperature.

(Accepted for publication January $17,1967$. ) 